\title{
RNAi-mediated downregulation of cyclin $Y$ to attenuate human breast cancer cell growth
}

\author{
FENG YAN $^{1,2}$, XIAOMING WANG ${ }^{2}$, MINGCHEN ZHU $^{2}$ and XIAOYA HU ${ }^{1}$ \\ ${ }^{1}$ College of Chemistry and Chemical Engineering, Yangzhou University, Yangzhou, Jiangsu 225002; \\ ${ }^{2}$ Department of Clinical Laboratory, Nanjing Medical University Cancer Hospital \\ and Jiangsu Cancer Hospital, Nanjing, Jiangsu 210009, P.R. China
}

Received October 20, 2015; Accepted November 26, 2015

DOI: $10.3892 /$ or.2016.5126

\begin{abstract}
Cyclin Y (CCNY) is a newly identified PFTK1 interacting protein and has been found to be associated with the proliferation and tumorigenesis of human non-small cell lung cancer. In the present study, we analyzed the expression levels of CCNY in 65 cases of breast cancer (BC) tissues and in four BC cell lines, BT-474, MDA-MB-231, T-47D and MCF-7. Lentivirus-mediated short hairpin RNA (shRNA) was employed to knock down CCNY expression in MCF-7 and MDA-MB-231 cells. The effects of CCNY depletion on cell growth were examined by MTT, colony formation and flow cytometry assays. The results showed that immunohistochemical expression of CCNY in tumor tissues is stronger than that in normal tissues. CCNY was also expressed in all four $\mathrm{BC}$ cells. The knockdown of CCNY resulted in a significant reduction in cell proliferation and colony formation ability. Cell cycle analysis showed that CCNY knockdown arrested MDA-MB-231 cells in the G0/G1 phase. Furthermore, depletion of CCNY inhibited BC cell growth via the activation of Bad and GSK3 $\beta$, as well as cleavages of PARP and caspase-3 in a p53-dependent manner. Therefore, we believe that CCNY has biological effect in BC development, and its inhibition via an RNA interference lentiviral system may provide a therapeutic option for $\mathrm{BC}$.
\end{abstract}

Correspondence to: Professor Xiaoya Hu, College of Chemistry and Chemical Engineering, Yangzhou University, 88 South University Avenue, Yangzhou, Jiangsu 225002, P.R. China

E-mail: xyhu@yzu.edu.cn

Abbreviations: CCNY, cyclin Y; BC, breast cancer; shRNA, short hairpin RNA; IDCs, invasive ductal carcinomas; ILC, invasive lobular carcinoma; CDKs, cyclin-dependent kinases; NSCLC, non-small cell lung cancer; DAB, 3,3'-diaminobenzidine; DMEM, Dulbecco's modified Eagle's medium; FBS, fetal bovine serum; MTT, methylthiazol tetrazolium; PI, propidium iodide

Key words: cyclin Y, breast cancer, lentivirus, downregulation, tumor tissue

\section{Introduction}

Breast cancer is the leading cause of cancer-related deaths in women worldwide, with $\sim 1.38$ million cases newly diagnosed and 458,000 deaths in 2008 alone $(1,2)$. According to the histopathological classification of breast carcinoma, 70-80\% of the all breast cancers will eventually belong to invasive ductal carcinomas (IDCs) or invasive lobular carcinoma (ILC) (3). There have been great advances in uncovering the biological mechanisms of breast cancer progression. However, many details of the genetic causes have yet to be determined.

Cyclins are a family of proteins that control cell cycle progression by regulating the activity of various cyclindependent kinases (CDKs) (4,5). Cyclin A1 was discovered to be highly expressed in primary breast cancer tissues and metastatic lesions, which leads to a significant increase in cancer cell growth and angiogenesis (6). Co-expression of cyclin D1 and p21 proteins is required for the initial steps of breast cancer development (7). Moreover, inhibition of cyclin D1 or its binding partners CDK4/6 can increase or decrease migration and stem-like cell activity in ER-negative and ER-positive breast cancer, respectively, showing estrogen receptor-dependent divergent functions (8). Cyclin D1 has also been reported to be associated with a poor prognosis for breast cancer patients $(9,10)$. High cyclin E expression is common in hormone receptor negative and high grade aggressive breast cancer (11-13). A meta-analysis has shown that cyclin E overexpression is associated with poor overall survival and breast cancer-specific survival (14).

Cyclin Y is a PFTK1 interacting protein newly identified using a yeast two-hybrid screen (15). Human PFTK1 protein has been characterized as a Cdc2-related kinase that controls cell cycle progression and is highly expressed in brain, pancreas and kidney (16). Binding of cyclin Y to PFTK1 not only enhances the PFTK1 kinase activity but also changes its intracellular location. Recently, cyclin Y was found to be overexpressed in human non-small cell lung cancer (NSCLC) and is associated with NSCLC proliferation and tumorigenesis (5). However, the role of cyclin $\mathrm{Y}$ in breast cancer remains elusive. The present study found that cyclin Y is highly expressed in human breast cancer specimens. To investigate the physiological function of cyclin $\mathrm{Y}$ in breast cancer, we applied gene knockdown using siRNA as an excellent tool to suppress cyclin $\mathrm{Y}$ expression in 
two types of breast cancer cells, MDA-MB-231 and MCF-7. The effects of cyclin $\mathrm{Y}$ on cell growth were also examined in two breast cancer cell lines.

\section{Materials and methods}

Immunohistochemical staining. Eighty cases of breast cancer tissues including 65 cases of breast cancer and 15 cases of nontumor tissues were collected from the Department of Clinical Laboratory, Nanjing Medical University Cancer Hospital and Jiangsu Cancer Hospital from 2008 to 2010. The clinical staging of breast cancer was evaluated by the tumor-nodemetastasis (TNM) staging systems. The samples were used with the written informed consent from patient and approval of the Ethics Committee of Nanjing Medical University Cancer Hospital and Jiangsu Cancer Hospital. All tissue samples were paraffin-embedded, dewaxed and rehydrated. The sections were then microwaved for antigen rerieval. For immunohistochemical staining, slides were treated with hydrogen peroxide $\left(\mathrm{H}_{2} \mathrm{O}_{2}\right)$ for $10 \mathrm{~min}$, washed with water and placed in phosphate-buffered saline (PBS) buffer. Anti-cyclin Y (1:150; \#ab114086; Abcam) was then applied for incubation at room temperature. Biotinylated goat anti-rabbit $\operatorname{IgG}$ was used as the secondary antibody. The immunoreactions were detected by staining with 3,3'-diaminobenzidine (DAB). All stained slides were evaluated under a light microscope. In each sample section, at least 5 visual field areas were examined. The proportion of positive tumor cells was recorded according to the following classification: 0 , no cells stained; $1,<30 \%$ of cells stained; $2,30-60 \%$ of cells stained and $3,>60 \%$ of cells stained. The intensity of the coloring was recorded according to the following classification: 0 , no coloring; 1 , stramineous; 2 , buffy; and 3, dark brown. The two scores were combined to obtain the final one: scores equal to 0 indicate negative (-), 1-2 indicate slightly positive $(+), 3-4$ indicate moderately positive (++), and 5-6 indicate strongly positive (+++).

Cell culture. Human breast cancer cell lines BT-474, MDA-MB-231, T-47D and MCF-7 and human embryonic kidney cell line 293T were obtained from the Cell Bank of Shanghai Institute of Cell Biology, Chinese Academy of Sciences (Shanghai, China). BT-474 cells were cultured in RPMI-1640 medium (HyClone) supplemented with $10 \%$ fetal bovine serum (FBS) in 5\% $\mathrm{CO}_{2}$ at $37^{\circ} \mathrm{C}$. MDA-MB-231, T-47D and 293T cells were grown in Dulbecco's modified Eagle's medium (DMEM; HyClone) supplemented with 10\% FBS in $5 \% \mathrm{CO}_{2}$ at $37^{\circ} \mathrm{C}$. MCF-7 cells were cultured in DMEM supplemented with $10 \%$ FBS, $1 \%$ sodium pyruvate and $0.01 \mathrm{mg} / \mathrm{ml}$ bovine insulin in $5 \% \mathrm{CO}_{2}$ at $37^{\circ} \mathrm{C}$.

Constructions of lentiviruses. A short hairpin RNA (shRNA) sequence (CCGGCAGGACAAATAGCAAGGAAATCTC GAGATTTCCTTGCTATTTGTCCTGTTTTTTG) was designed for human cyclin Y gene (NM_145012.3). The nonsilencing siRNA sequence (TTCTCCGAACGTGTCACGT) was used as control. The stem-loop-stem oligos (shRNAs) were ligated into the $\mathrm{pFH}-\mathrm{L}$ vector containing a GFP reporter (Shanghai Hollybio, China). 293T cells were transfected with pFH-L-cyclin Y shRNA or control shRNA along with two helper plasmids pVSVG-I and pCMVAR8.92 (Shanghai
Hollybio, China) using Lipofectamine 2000 (Invitrogen) according to the manufacturer's instructions. Lentiviruses were harvested $72 \mathrm{~h}$ after transfection. The lentiviruses were purified using ultracentrifugation, and the titer of the lentiviruses was determined. MDA-MB-231 $\left(5 \times 10^{4}\right.$ cells/well $)$ and

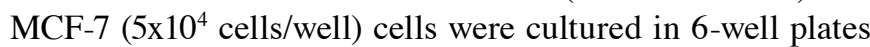
and infected with the lentivirus constructs at a multiplicity of infection (MOI) of 40 and 30, respectively. The transfection efficiency was determined by fluorescence microscopy $96 \mathrm{~h}$ after infection.

Quantitative real-time PCR. After infection for $96 \mathrm{~h}$, MDA-MB-231 and MCF-7 cells were collected for RNA extraction by TRIzol (Invitrogen, Carlsbad, CA, USA). Total RNA $(2 \mu \mathrm{g})$ was reverse transcribed using an M-MLV reverse transcriptase kit (Promega) according to the manufacturer's protocol. In quantitative real-time PCR, two sets of primers were applied: cyclin Y sense, 5'-GTCAGTCAACCAAACCT CAAG-3' and antisense, 5'-AACAGTGTCCGAACGAA CC-3'; $\beta$-actin sense, 5'-GTGGACATCCGCAAAGAC-3' and antisense, 5'-AAAGGGTGTAACGCAACTA-3'. Relative expression levels of cyclin $\mathrm{Y}$ mRNA were calculated by normalizing to the level of $\beta$-actin mRNA using comparative threshold cycle method, in which the fold difference $=2-(\Delta \mathrm{ct}$ of target gene - $\Delta$ ct of reference). Each sample was performed in triplicate. All results were analyzed with LightCycler software version 3.5 (Roche Diagnostics).

MTT assay. After infection with recombined lentiviruses (Lv-shCCNY and Lv-shCon), MDA-MB-231 (2x10 cells/well) or MCF-7 ( $2 \times 10^{3}$ cells/well) cells were reseeded into 96-well plates, and were collected at 1-day intervals to perform the methylthiazol tetrazolium (MTT) proliferation assay. In brief, $10 \mu \mathrm{l}$ of MTT solution $(5 \mathrm{mg} / \mathrm{ml}$; Sigma) was added into each well and incubated at $37^{\circ} \mathrm{C}$ for $4 \mathrm{~h}$. Acidic isopropanol $(10 \%$ SDS, $5 \%$ isopropanol and $0.01 \mathrm{~mol} / \mathrm{l} \mathrm{HCl}$ ) was then added to dissolve the crystals. After $10 \mathrm{~min}$, the absorbance of each sample was recorded at $595 \mathrm{~nm}$.

Colony formation assay. MDA-MB-231 (400 cells/well) or MCF-7 (200 cells/well) cells were reseeded in 6-well plates after lentivirus infection. The medium was changed at three-day intervals. After 6 days of culture for MDA-MB-231 cells and 8 days of culture for MCF-7 cells, the colonies formed were washed with PBS and fixed with 4\% paraformaldehyde for $30 \mathrm{~min}$ at room temperature. The fixed cell samples were stained with crystals violet for $10 \mathrm{~min}$. The total number of colonies ( $>50$ cells/colony) was counted.

Flow cytometric analysis. Fluorescence dye propidium iodide (PI) (Sigma) was used to analyze the DNA contents in different cell cycle phases. MDA-MB-231 $\left(2 \times 10^{5}\right.$ cells/ well) cells infected with $\mathrm{Lv}$-shcyclin $\mathrm{Y}$ and $\mathrm{Lv}$-shCon were reseeded into 6- $\mathrm{cm}$ dishes and cultured for $40 \mathrm{~h}$ and harvested after trypsinization, washed with PBS and fixed with $70 \%$ cold ethanol. The fixed cells were pelleted, re-suspended in PBS containing PI $(100 \mu \mathrm{g} / \mathrm{ml})$ and RNase A $(10 \mu \mathrm{g} / \mathrm{ml})$ for at least $30 \mathrm{~min}$ in the dark. The percentages of cells in G0/G1, $\mathrm{S}$ and $\mathrm{G} 2 / \mathrm{M}$ phases were determined by FACSCalibur (BD Biosciences, USA). 

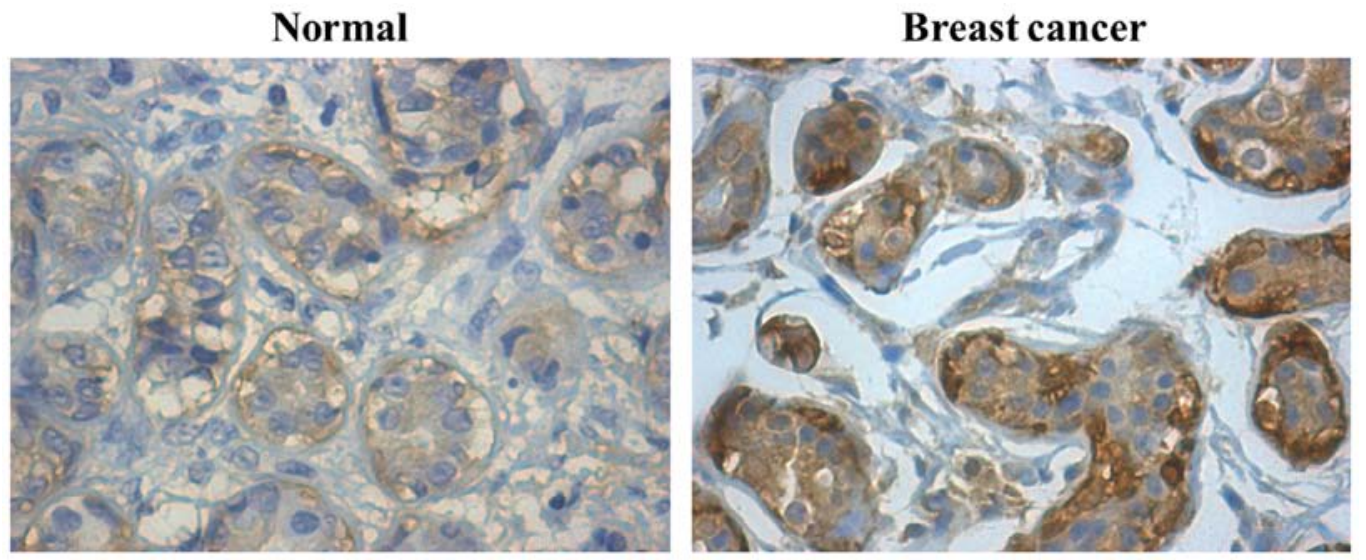

Figure 1. Determination of cyclin Y expression by immunohistochemical staining. Normal (left) and breast cancer (right) tissue specimens are subjected to immunohistochemical staining. Brown stained areas are DAB-positive (cyclin Y-positive). Magnification, $x 400$.

Table I. Expression of cyclin $Y$ in normal breast and breast cancer tissues $(n=80)$.

\begin{tabular}{|c|c|c|c|c|c|c|}
\hline \multirow[b]{2}{*}{ Characteristics } & \multirow[b]{2}{*}{ Total } & \multicolumn{4}{|c|}{ Cyclin Y immunostaining } & \multirow[b]{2}{*}{ P-value } \\
\hline & & $-(\%)$ & $+(\%)$ & $++(\%)$ & $+++(\%)$ & \\
\hline Normal breast & 15 & $0(0.0)$ & $4(26.7)$ & $10(66.7)$ & $1(6.7)$ & 0.037 \\
\hline Breast cancer & 65 & $0(0.0)$ & $12(18.5)$ & $26(40.0)$ & $27(41.5)$ & \\
\hline
\end{tabular}

${ }^{a} U$ sing Pearson's $\chi^{2}$ test.

Intracellular signaling assay. Phosphorylation and proteolysis are two widespread covalent post-translational modifications. Detection of these modifications on a set of cellular proteins that play a well-understood role in cell biology can provide a broad snapshot of intracellular signaling. The alteration of signaling molecules in MDA-MB-231 cells was detected by PathScan ${ }^{\circledR}$ intracellular signaling array kit (\#7323; Cell Signaling Technology) according to the protocol provided by CST.

Statistical analysis. The results of immunohistochemical staining were evaluated by Pearson's $\chi^{2}$ test and the other data were evaluated by Student's t-test and expressed as the mean \pm SD of three independent experiments. A p-value of $<0.05$ was considered to indicate a statistically significant result.

\section{Results}

Cyclin $Y$ expression in human breast cancer and normal breast tissues. The expression patterns of cyclin Y protein in 65 stage I-III breast cancer and 15 normal breast tissues were analyzed by immunohistochemistry. Representative immunohistochemical staining is shown in Fig. 1. The rate of strong cyclin $\mathrm{Y}$ expression (+++) in breast cancer tissues was significantly higher than that in normal breast tissues (Table I; $\mathrm{p}<0.05 ; \chi^{2}$ test). Moreover, the expression of cyclin $\mathrm{Y}$ in breast cancer was associated with lymph node metastasis (Table II; $\mathrm{p}<0.001 ; \chi^{2}$ test). These results suggest that the high cyclin $\mathrm{Y}$ expression may contribute to breast cancer development and progression.
Table II. Relationship of cyclin Y expression and clinicopathological parameters in breast cancer patients $(n=65)$.

\begin{tabular}{|c|c|c|c|c|c|}
\hline \multirow[b]{2}{*}{ Characteristic } & \multicolumn{4}{|c|}{$\begin{array}{l}\text { Cyclin Y } \\
\text { immunostaining }\end{array}$} & \multirow[b]{2}{*}{ P-value ${ }^{a}$} \\
\hline & - & + & ++ & +++ & \\
\hline Stage & & & & & 0.458 \\
\hline I & 0 & 0 & 1 & 2 & \\
\hline II & 0 & 12 & 23 & 21 & \\
\hline III & 0 & 0 & 2 & 4 & \\
\hline Invasion depth & & & & & 0.139 \\
\hline I & 0 & 0 & 1 & 0 & \\
\hline II & 0 & 3 & 3 & 13 & \\
\hline III & 0 & 9 & 8 & 11 & \\
\hline Lymph node metastasis & & & & & 0.001 \\
\hline No & 0 & 1 & 17 & 20 & \\
\hline Yes & 0 & 11 & 9 & 5 & \\
\hline
\end{tabular}

${ }^{\mathrm{a}}$ Using Pearson's $\chi^{2}$ test.

Inhibition of cyclin $Y$ expression by RNA interference. The expression levels of cyclin $\mathrm{Y}$ in four human breast cancer cell lines were analyzed by RT-qPCR (Fig. 2A). The MCF-7 (ER-positive) cells with high cyclin $\mathrm{Y}$ expression and MDA-MB-231 (ER-negative) cells with low cyclin Y 
$\mathbf{A}$

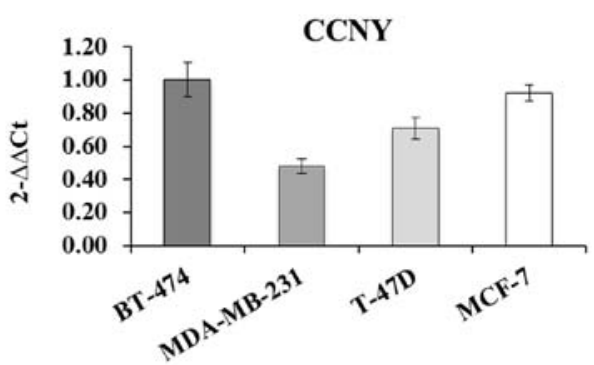

B

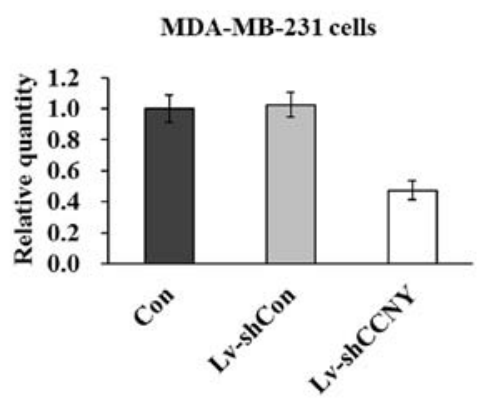

D

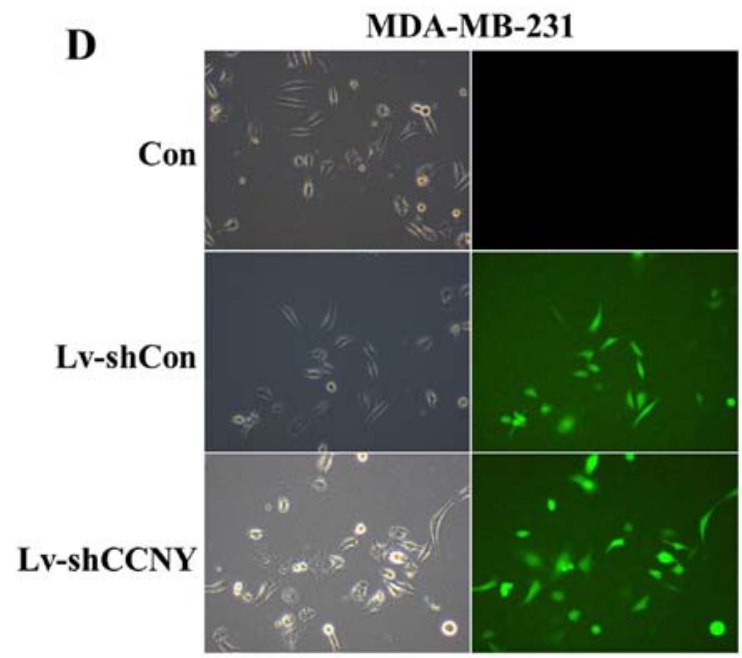

C

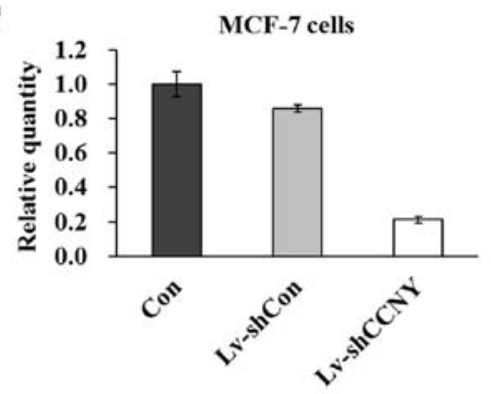

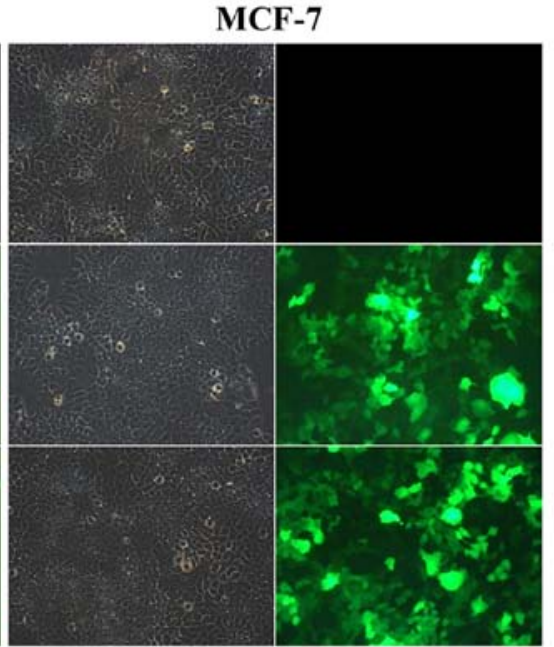

Figure 2. Efficient transfection with lentivirus targeting cyclin Y in breast cancer cells. (A-C) The mRNA and protein levels of cyclin Y in breast cancer cells are determined by RT-qPCR and western blotting. (D) Seventy-two hours post-transfection, treated cells were photographed under bright light and fluorescent light in MCF-7 (left panel) and MDA-MB-231 (right panel) cells with original magnification, x200.

expression were chosen for further investigation. The cells were treated with Lv-shcyclin Y and Lv-shCon. To determine the transfection efficiency, fluorescent cells were examined and photographed. As shown in Fig. 2D, $>80 \%$ of cells were GFP-positive, indicating that both MCF-7 and MDA-MB-231 cells were successfully transfected. The mRNA levels of cyclin $\mathrm{Y}$ were then measured to assess the knockdown efficiency of Lv-shcyclin Y. As compared to Lv-shCon, the Lv-shcyclin Y conferred $\sim 60 \%$ knockdown efficiency in both MDA-MB-231 (Fig. 2B) and MCF-7 cells (Fig. 2C). The results indicated that the lentivirus constructs were able to efficiently suppress cyclin Y expression in both MDA-MB-231 and MCF-7 cells.

Cyclin $Y$ knockdown suppresses proliferation of $M D A-M B-231$ and MCF-7 cells. To evaluate the biological effect of cyclin $\mathrm{Y}$ knockdown in regulating breast cancer cell proliferation, MTT and colony formation assays were used. As shown in Fig. 3, the growth curves of Lv-shcyclin Y groups were much lower than those of Lv-shCon and control groups in both MDA-MB-231 and MCF-7 cells. The results showed that the Lv-shcyclin Y had a short-term inhibitory effect on cell proliferation. Moreover, we further determined its relative long-term function on cell proliferation by colony formation assay. As revealed in Fig. 4A, the size of single colony in the Lv-shcyclin $\mathrm{Y}$ group was much smaller than that in Lv-shCon and control groups. Also, the total number of colonies formed in MDA-MB-231 cells was markedly reduced by over $80 \%$ in the Lv-shcyclin Y group (Fig. 4B). These results indicated that cyclin Y knockdown inhibited the proliferation of breast cancer cells.

Cyclin Y knockdown induces cell cycle arrest at G0/G1 phase. To investigate whether cyclin Y regulates cell cycle progression directly, we then examined the cell cycle distribution of MDA-MB-231 cells after cyclin Y knockdown by flow cytometry. As shown in Fig. 5, compared with control 
A

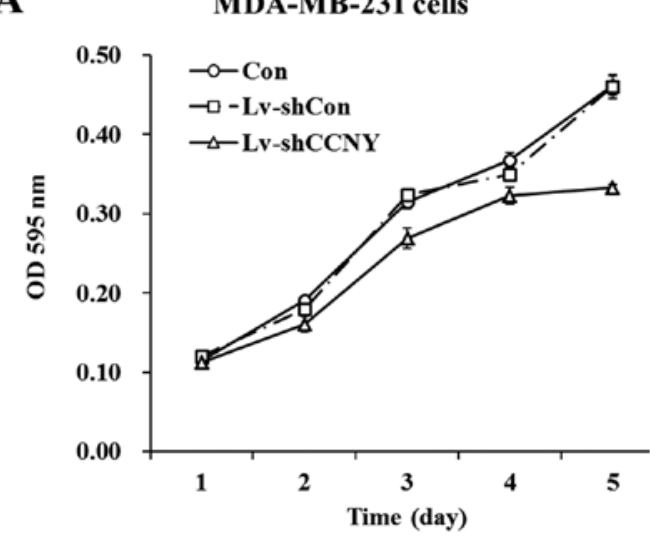

B

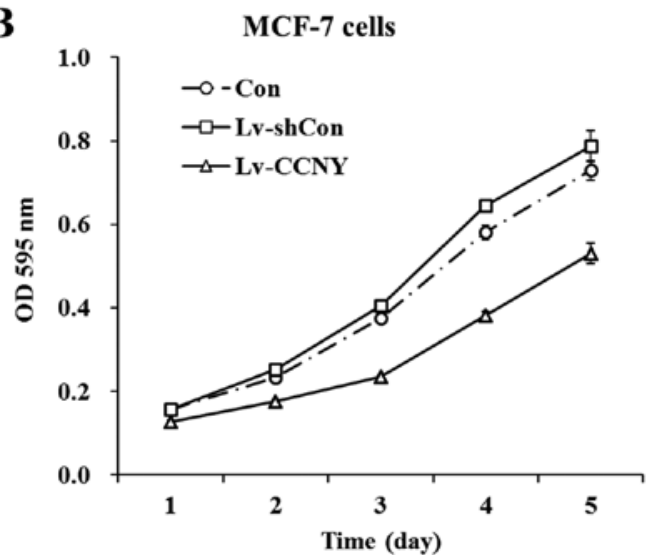

Figure 3. Effect of cyclin Y knockdown on the proliferation of breast cancer MCF-7 (A) and MDA-MB-231 (B) cells. Cells with Lv-shcyclin Y, Lv-shCon and Con treatments were determined by MTT assay with 1-day intervals.

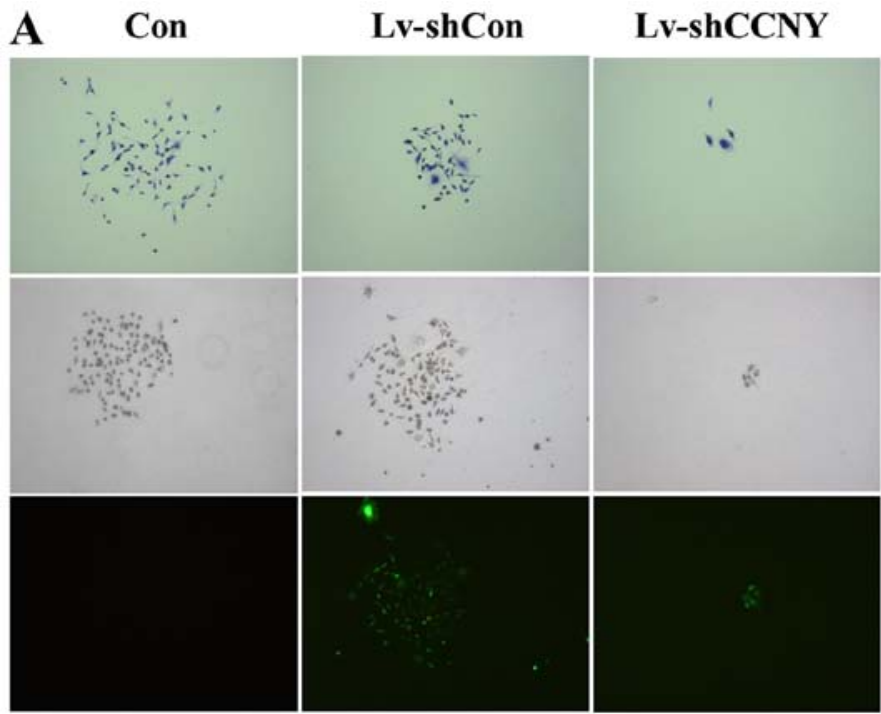

B

MDA-MB-231 cells

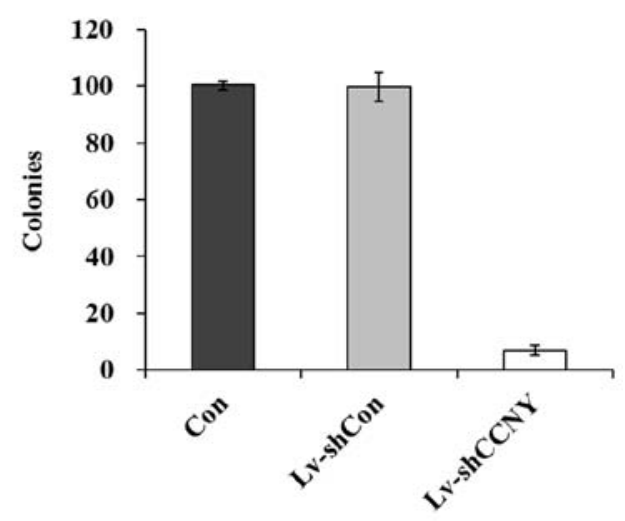

Figure 4. Inhibition of the colony-forming ability of MDA-MB-231 cells through cyclin Y knockdown. (A) Representative images of colonies with Giemsa staining under light microscopy and fluorescence microscopy. (B) Statistical analysis of the number of colonies in MDA-MB-231 cells with Lv-shCCNY, Lv-shCon and Con treatments.

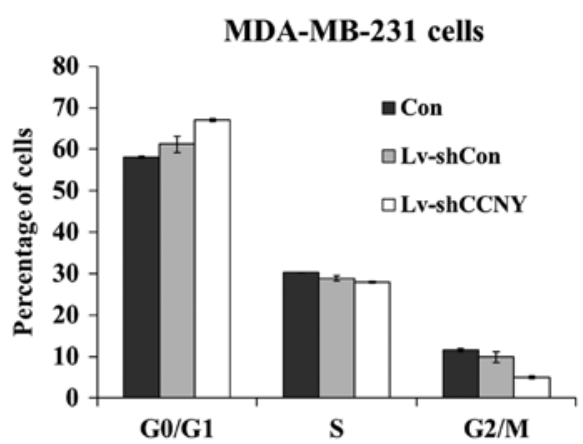

Figure 5. Cyclin Y knockdown induces cell cycle of MDA-MB-231 cells. Cell cycle distribution of MDA-MB-231 cells is analyzed by flow cytometry. The population of cells in the G0/G1 phase increased in Lv-shcyclin Y group.

and $\mathrm{Lv}$-shCon groups, the proportion of cells increased in the G0/G1 phase and decreased in the G2/M phase, indicating that cyclin $\mathrm{Y}$ could be involved in the cell cycle regulation.
Modifications of effector proteins in cyclin Y-silenced cells. To explore the underlying signaling pathways mediated by cyclin $\mathrm{Y}$ in breast cancer cells, PathScan ${ }^{\circledR}$ intracellular signaling array kit was utilized to test whether alterations of modifications occurred in proteins involved in cell proliferation, growth, cell cycle, survival or apoptosis (Fig. 6). The detection of signaling pathways contained the MAPK/ERK cascade, $\mathrm{p} 38$ and JNK MAPKs, Stat1 and Stat3, Akt, mTOR, AMPK, HSP27, p53, and caspase-3. To our surprise, knockdown of cyclin $\mathrm{Y}$ in MDA-MB-231 cells resulted in a series of phosphorylation, including Bad (Ser112), p53 (Ser15), GSK3 $\beta$ (Ser9), as well as cleavage of PARP and caspase-3 (Table III). These data indicated that the above signaling pathways could contribute to the regulation of cyclin $\mathrm{Y}$ in breast cancer cell growth.

\section{Discussion}

Cyclins are essential regulators of cell cycle progression and are implicated in cancer progression. Abnormalities in cell 

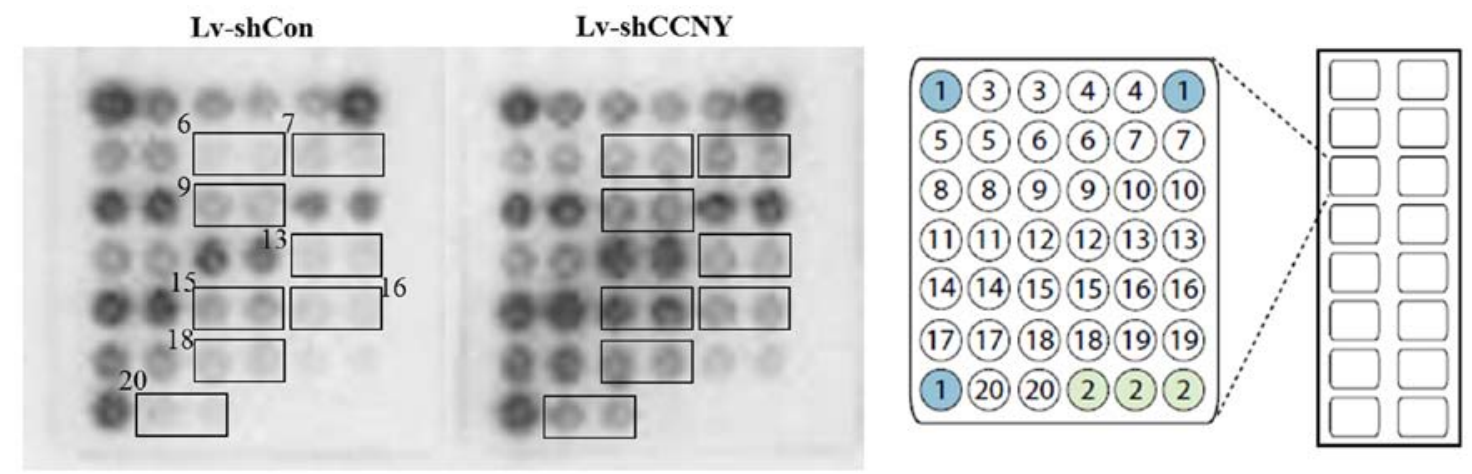

Figure 6. Alterations of protein modification with intracellular signaling assay. Modifications of effector proteins are analyzed in MDA-MB-231 cells from two groups. The data can be directly read out from the spot intensity showed in the left graph. The distribution of 20 protein modifications in one chip is shown in the graph on the right.

Table III. Representative modification from different wells in one chip.

\begin{tabular}{clllc}
\hline Target & Phosphorylation & \multicolumn{1}{c}{ Site } & Modification & Lv-shcyclin Y vs. Lv-shCon \\
\hline 6 & Akt & Thr308 & Phosphorylation & Upregulation \\
7 & Akt & Ser473 & Phosphorylation & Upregulation \\
9 & S6 ribosomal & Ser235/236 & Phosphorylation & Upregulation \\
13 & p70 S6 kinase & Thr389 & Phosphorylation & Upregulation \\
15 & p53 & Ser15 & Phosphorylation & Upregulation \\
16 & p38 & Thr180/Tyr182 & Phosphorylation & Upregulation \\
18 & PARP & Asp214 & Cleavage & Upregulation \\
19 & Caspase-3 & Asp175 & Cleavage & Upregulation \\
\hline
\end{tabular}

cycle regulatory proteins are common in breast cancers (17). The present study indicates that cyclin $\mathrm{Y}$ is highly expressed in human breast cancer specimens. To identify cyclin Y involved in breast cancer development and progression, lentivirus-mediated RNAi was employed to knock down cyclin Y expression in two types of breast cancer cells, the MDA-MB-231 and MCF-7 cells. Inhibition of cyclin Y markedly attenuated the cell proliferation and colony formation capacity.

$\mathrm{Xu}$ et al have reported that cyclin $\mathrm{Y}$ may function as a S-phase-related cyclin, similar to cyclin A-CDK2 (18). CDK16 can be activated by membrane-associated cyclin Y (19). Unlike conventional cyclin-CDK interactions, cyclin Y-CDK16 binding not only requires the catalytic domain, but also domains within the N-terminal region (20). To examine the effect of cyclin $\mathrm{Y}$ on the cell cycle control in breast cancer, flow cytometry analysis was performed. Knockdown of cyclin $\mathrm{Y}$ in MDA-MB-231 cells resulted in G0/G1 phase cell cycle arrest, which could contribute to cell growth inhibition, indicating that cyclin Y may directly participate in G1/S transition. We next sought to determine the underlying molecular mechanism by which cyclin Y regulated breast cancer cell growth. Depletion of cyclin Y augmented the phosphorylation of Bad, p53, GSK3 $\beta$ and the cleavages of PARP and caspase-3. Phosphorylation of the pro-apoptotic protein Bad inhibits cell proliferation and promotes apoptosis while its inhibition increases cell growth rate (21). Phosphorylation of the multifunctional kinase GSK-3 $\beta$ at Ser9 $(22,23)$ inhibits its activity. Inhibition of GSK-3 $\beta$ enhances reovirus-induced apoptosis in colon cancer cells (24). Increased levels of cleaved caspase-3 and cleaved PARP are reliable indicators of apoptosis (25). The above results suggested that cyclin Y knockdown could induce apoptosis by activating Bad, GSK-3 $\beta$, PARP and caspase- 3 in a p53-dependent manner, which also contribute to cell growth inhibition.

In conclusion, cyclin $\mathrm{Y}$ is overexpressed in breast cancer and modulates cell growth progression via regulating cell cycle progression and apoptosis. A lentiviral-mediated RNAi system may be an ideal therapeutic option for breast cancer therapy.

\section{Acknowledgements}

The present study was financially supported by the National Natural Science Foundation of China (21475063), the Chinese Jiangsu Provincial Special Program of Medical Science (BL2013036), and the Grand of Medicine Leading Talents of Jiangsu Health Department of China (LJ201131).

\section{References}

1. Banerji S, Cibulskis K, Rangel-Escareno C, Brown KK, Carter SL, Frederick AM, Lawrence MS, Sivachenko AY, Sougnez C, Zou L, et al: Sequence analysis of mutations and translocations across breast cancer subtypes. Nature 486: 405-409, 2012.

2. Jemal A, Bray F, Center MM, Ferlay J, Ward E and Forman D: Global cancer statistics. CA Cancer J Clin 61: 69-90, 2011.

3. Viale G: The current state of breast cancer classification. Ann Oncol 23 (Suppl 10): x207-x210, 2012 
4. Nagano T, Hashimoto T, Nakashima A, Hisanaga S, Kikkawa U and Kamada S: Cyclin I is involved in the regulation of cell cycle progression. Cell Cycle 12: 2617-2624, 2013.

5. Yue W, Zhao X, Zhang L, Xu S, Liu Z, Ma L, Jia W, Qian Z, Zhang $\mathrm{C}$, Wang Y, et al: Cell cycle protein cyclin Y is associated with human non-small-cell lung cancer proliferation and tumorigenesis. Clin Lung Cancer 12: 43-50, 2011.

6. Syed Khaja AS, Dizeyi N, Kopparapu PK, Anagnostaki L, Härkönen P and Persson JL: Cyclin A1 modulates the expression of vascular endothelial growth factor and promotes hormonedependent growth and angiogenesis of breast cancer. PLoS One 8: e72210, 2013.

7. Dai M, Al-Odaini AA, Fils-Aimé N, Villatoro MA, Guo J, Arakelian A, Rabbani SA, Ali S and Lebrun J: Cyclin D1 cooperates with $\mathrm{p} 21$ to regulate TGF $\beta$-mediated breast cancer cell migration and tumor local invasion. Breast Cancer Res 15: R49, 2013.

8. Lamb R, Lehn S, Rogerson L, Clarke RB and Landberg G: Cell cycle regulators cyclin D1 and CDK4/6 have estrogen receptordependent divergent functions in breast cancer migration and stem cell-like activity. Cell Cycle 12: 2384-2394, 2013.

9. Aaltonen K, Amini RM, Landberg G, Eerola H, Aittomäki K, Heikkilä P, Nevanlinna H and Blomqvist C: Cyclin D1 expression is associated with poor prognostic features in estrogen receptor positive breast cancer. Breast Cancer Res Treat 113: 75-82, 2009

10. Wei M, Zhu L, Li Y, Chen W, Han B, Wang Z, He J, Yao H, Yang Z, Zhang Q, et al: Knocking down cyclin Dlb inhibits breast cancer cell growth and suppresses tumor development in a breast cancer model. Cancer Sci 102: 1537-1544, 2011.

11. Sgambato A, Camerini A, Collecchi P, Graziani C, Bevilacqua G, Capodanno A, Migaldi M, Masciullo V, Scambia G, Rossi G, et al: Cyclin E correlates with manganese superoxide dismutase expression and predicts survival in early breast cancer patients receiving adjuvant epirubicin-based chemotherapy. Cancer Sci 100: 1026-1033, 2009.

12. Shaye A, Sahin A, Hao Q, Hunt K, Keyomarsi K and Bedrosian I: Cyclin E deregulation is an early event in the development of breast cancer. Breast Cancer Res Treat 115: 651-659, 2009.

13. Waltersson MA, Askmalm MS, Nordenskjöld B, Fornander T, Skoog L and Stål O: Altered expression of cyclin E and the retinoblastoma protein influences the effect of adjuvant therapy in breast cancer. Int J Oncol 34: 441-448, 2009.
14. Gao S, Ma JJ and Lu C: Prognostic value of cyclin E expression in breast cancer: A meta-analysis. Tumour Biol 34: 3423-3430, 2013.

15. Jiang M, Gao Y, Yang T, Zhu X and Chen J: Cyclin Y, a novel membrane-associated cyclin, interacts with PFTK1. FEBS Lett 583: 2171-2178, 2009.

16. Yang $\mathrm{T}$ and Chen JY: Identification and cellular localization of human PFTAIRE1. Gene 267: 165-172, 2001.

17. Ahlin C, Zhou W, Holmqvist M, Holmberg L, Nilsson C, Jirström K, Blomqvist C, Amini RM and Fjällskog ML: Cyclin A is a proliferative marker with good prognostic value in node-negative breast cancer. Cancer Epidemiol Biomarkers Prev 18: 2501-2506, 2009.

18. Xu Y, Wang Z, Wang J, Li J, Wang $\mathrm{H}$ and Yue W: Lentivirusmediated knockdown of cyclin Y (CCNY) inhibits glioma cell proliferation. Oncol Res 18: 359-364, 2010.

19. Mikolcevic P, Sigl R, Rauch V, Hess MW, Pfaller K, Barisic M, Pelliniemi LJ, Boesl M and Geley S: Cyclin-dependent kinase 16/PCTAIRE kinase 1 is activated by cyclin Y and is essential for spermatogenesis. Mol Cell Biol 32: 868-879, 2012.

20. Mikolcevic P, Rainer J and Geley S: Orphan kinases turn eccentric: A new class of cyclin Y-activated, membrane-targeted CDKs. Cell Cycle 11: 3758-3768, 2012.

21. Konishi Y, Lehtinen M, Donovan N and Bonni A: Cdc2 phosphorylation of BAD links the cell cycle to the cell death machinery. Mol Cell 9: 1005-1016, 2002.

22. Cross DA, Alessi DR, Cohen P, Andjelkovich M and Hemmings BA: Inhibition of glycogen synthase kinase- 3 by insulin mediated by protein kinase B. Nature 378: 785-789, 1995.

23. Jacobs KM, Bhave SR, Ferraro DJ, Jaboin JJ, Hallahan DE and Thotala D: GSK-3 $\beta$ : A bifunctional role in cell death pathways. Int J Cell Biol 2012: 930710, 2012.

24. Min HJ, Koh SS, Cho IR, Srisuttee R, Park EH, Jhun BH, Kim YG, Oh S, Kwak JE, Johnston RN, et al: Inhibition of GSK-3 $\beta$ enhances reovirus-induced apoptosis in colon cancer cells. Int J Oncol 35: 617-624, 2009.

25. Bressenot A, Marchal S, Bezdetnaya L, Garrier J, Guillemin F and Plénat F: Assessment of apoptosis by immunohistochemistry to active caspase-3, active caspase-7, or cleaved PARP in monolayer cells and spheroid and subcutaneous xenografts of human carcinoma. J Histochem Cytochem 57: 289-300, 2009. 